\title{
Morphology and Viscoelastic Properties of Quarternized Poly(styrene-b-butadiene-b-4-vinylpyridine) Three-Block Polymers
}

\author{
Itaru Kudose, ${ }^{\text {a }}$ Koichi ARAI, ${ }^{\text {b }}$ and Tadao KotaKA* \\ Department of Macromolecular Science, Faculty of Science, \\ Osaka University, Toyonaka, Osaka 560, Japan
}

(Received December 3, 1983)

\begin{abstract}
Poly(4-vinylpyridine) (P4VP) blocks in solvent-cast films of poly(styrene- $b$ butadiene- $b$-4-vinylpyridine) (SBP) three-block polymers were quarternized by a vapor phase reaction with $\mathrm{CH}_{3} \mathrm{Br}$ at $70^{\circ} \mathrm{C}(0.4$ to $0.7 \mathrm{~atm})$. The yield was nearly $100 \%$. No changes in morphology were observed before or after quarternization in any SBP specimens cast from different solvents and hence of different morphology. The temperature-complex moduli curves of all the specimens in which isolated P4VP domains are wrapped with polybutadiene (PB) blocks surrounded by the polystyrene (PS) matrix (a "ball-in-a-box" morphology) received no effects from quarternization. Both unquarternized and quarternized specimens with this morphology exhibited only two mechanical transitions due to PB and PS phases (about 190 and $370 \mathrm{~K}$, respectively). The unquarternized specimens having continuous P4VP domains ("three-layer-lamellar" morphology) exhibited three transitions due to the three components, and the quarternization significantly increased dynamic moduli above the glass transition temperature $(430 \mathrm{~K}$ ) of the P4VP phase.

KEY WORDS Block Polymer / Block Terpolymer / ABC Type Block

Polymer / Poly(styrene- $b$-butadiene- $b$-4-vinylpyridine) / Morphology /

Viscoelastic Properties / Quarternization /
\end{abstract}

Our previous publications ${ }^{1-4}$ described the synthesis, morphology and mechanical properties of poly(styrene- $b$-butadiene- $b$-4-vinylpyridine) three-block polymers of $\mathrm{ABC}$ type, which are referred to as SBP polymers. We considered it interesting to ionize the poly(4-vinylpyridine) (P4VP) and polystyrene (PS) blocks of these SBP polymers to prepare a charge mosaic membrane, utilizable as an active transport membrane. As the first step to this end, we tried to quarternize P4VP blocks. However, according to Fielding-Russel et al., 5 the morphology of PS-polybutadiene (PB)poly(2-vinylpyridine) (P2VP) three-block polymers is greatly altered by quarternization of
P2VP blocks with $\mathrm{HCl}$. If such a change occurs, the definite morphological features of the SBP membranes would be lost. Therefore, efforts were made to quarternize P4VP blocks in SBP membranes without destroying the morphology. In this article, we report some results from such an attempt, especially the morphology and dynamic mechanical properties of SBP specimens before and after quarternization.

\section{EXPERIMENTAL}

The methods of synthesis of SBP polymers $^{2,4}$ and poly(styrene- $b$-4-vinylpyridine)

\footnotetext{
${ }^{a}$ Present address: Plastics Engineering Department, Mizushima Factory, Mitsubishi Chemical Industries Inc. Kurashiki, Okayama 712, Japan.

b Present address: Tokyo Research Laboraroty, Japan Synthetic Rubber Co., Ltd., Asao-ku, Kawasaki 214, Japan.

* To whom all correspondence should be addressed.
} 
Table I. Characteristics of the polymer samples ${ }^{\mathrm{a}, \mathrm{b}}$

\begin{tabular}{|c|c|c|c|c|c|c|c|c|}
\hline \multirow{2}{*}{ Code } & \multicolumn{5}{|c|}{ Number average values $10^{-3} M_{n}$} & \multicolumn{3}{|c|}{ Volume compositions } \\
\hline & $M_{n}^{\mathrm{s} \cdot}$ & $\left(M_{w} / M_{n}\right)^{\mathrm{S}}$ & $M_{n}^{\mathrm{B}}$ & $M_{n}^{\mathrm{P}}$ & $M_{n t}$ & $\phi_{\mathrm{S}}$ & $\phi_{\mathrm{B}}$ & $\phi_{\mathrm{P}}$ \\
\hline SBP-1 & 20.2 & $(1.06)$ & 22.0 & 32.3 & 74.5 & 0.26 & 0.34 & 0.40 \\
\hline SBP-10 & 30.1 & $(1.08)$ & 14.3 & 28.5 & 72.9 & 0.41 & 0.23 & 0.36 \\
\hline SBP-11 & 23.3 & $(1.08)$ & 14.2 & 19.7 & 57.2 & 0.40 & 0.29 & 0.32 \\
\hline SP-2 & 35.9 & $(1.22)$ & - & 40.8 & 76.7 & 0.48 & - & 0.52 \\
\hline SBS $^{c}$ & 13.2 & - & 53.8 & - & 80.3 & 0.29 & 0.71 & - \\
\hline
\end{tabular}

${ }^{a} M_{n}^{\mathrm{S}}, M_{n}^{\mathrm{B}}, M_{n}^{\mathrm{P}}$ and $M_{n t}$ denote the number average molecular weights of PS, PB, and P4VP blocks, and the whole molecule, respectively. The $\left(M_{w} / M_{n}\right)^{\mathrm{S}}$ values were determined for the PS precursors.

${ }^{\mathrm{b}}$ For the weight fractions $x_{\mathrm{S}}: x_{\mathrm{B}}: x_{\mathrm{P}}=M_{n}^{\mathrm{S}}: M_{n}{ }^{\mathrm{B}}: M_{n}{ }^{\mathrm{P}}$, while for the volume fractions

$$
\phi_{\mathrm{S}}: \phi_{\mathrm{B}}: \phi_{\mathrm{P}}=M_{n}^{\mathrm{s}} / \rho_{\mathrm{S}}: M_{n}^{\mathrm{B}} / \rho_{\mathrm{B}}: M_{n}^{\mathrm{P}} / \rho_{\mathrm{P}}
$$

with the bulk densities $\rho_{\mathrm{S}}=1.05, \rho_{\mathrm{B}}=0.89$, and $\rho_{\mathrm{P}}=1.114 \mathrm{~g} \mathrm{~cm}^{-3}$.

c Shell Chemical Kraton 1101.

(SP) diblock copolymers and the preparation of specimens with different morphology have been reported elsewhere. ${ }^{3,4}$ A styrene (S) butadiene (B) block copolymer sample of SBS type (Kraton 1101, Shell Chem. Co.) was used as a reference. Table I lists the characteristics of the samples used in this study.

Films for later quarternization experiments were prepared by casting from $3 \mathrm{wt} \%$ solutions. The casting solvents were $\mathrm{CHCl}_{3}$, mixtures of tetrahydrofuran (THF)/methanol $(\mathrm{MeOH})(4 / 1$ by volume ratio, v/v), THF/ ethanol $(\mathrm{EtOH})(4 / 1, \mathrm{v} / \mathrm{v})$, or benzene $(\mathrm{BZ}) /$ $\mathrm{EtOH}(4 / 1, \mathrm{v} / \mathrm{v}) . \mathrm{MeOH}$ and $\mathrm{EtOH}$ are good solvents for $\mathrm{P} 4 \mathrm{VP}$, while $\mathrm{CHCl}_{3}$ and $\mathrm{BZ}$ are good solvents for PS and PB. THF is a good solvent for PS but somewhat poor for PB and P4VP. All the films obtained were tough and transparent.

Quarternization was carried out with $\mathrm{CH}_{3} \mathrm{Br}$ by the vapor phase method reported by Platt and Schindler. ${ }^{6}$ Usually, a film 0.2 to $0.5 \mathrm{~mm}$ thick was placed in a separable flask and dried under vacuum at room temperature for $24 \mathrm{~h}$. After drying, $\mathrm{CH}_{3} \mathrm{Br}$ was introduced into the flask for reaction with the film. Two sets of conditions were employed: at about $90^{\circ} \mathrm{C}$, $1 \mathrm{~atm} \mathrm{CH}_{3} \mathrm{Br}$ vapor, $14 \mathrm{~h}$; and at about $70^{\circ} \mathrm{C}$, about 0.4 to $0.7 \mathrm{~atm}$ vapor, $48 \mathrm{~h}$. Under the former conditions, the films changed color slightly. After the reaction, the film was dried under vacuum for several days to remove any unreacted $\mathrm{CH}_{3} \mathrm{Br}$. The degree of quarternization was determined by elemental analysis of bromine.

Electron micrographs were taken on a Hitachi HV-12 transmission electron microscope at an operating voltage of $75 \mathrm{kV}$. The films were trimmed and exposed to osmium tetraoxide vapor over a $1 \%$ aqueous solution at room temperature for 4 days. The films were then microtomed into sections about 40 to $60 \mathrm{~nm}$ thick in two mutually perpendicular directions both normal to the film surface.

Complex tensile moduli $E^{*}$ were measured with a Rheovibron DDV-II (Toyo Baldwin Co.) at $110 \mathrm{~Hz}$ over a temperature range from 150 to $450 \mathrm{~K}$ at a heating rate of about $1 \mathrm{~K} \mathrm{~min}^{-1}$. The thermal properties were investigated with a differential scanning calorimeter (DSC; Rigaku Denki Co., Model 8055). Usually, data were taken in a temperature range from 150 to $473 \mathrm{~K}$ at a heating rate of $10 \mathrm{~K} \mathrm{~min}^{-1}$. Measurements were sometimes made up to a polymer decomposition temperature of about $600 \mathrm{~K}$.

\section{RESULTS AND DISCUSSION}

For an SBP-1 sample, lamellar, complicated 


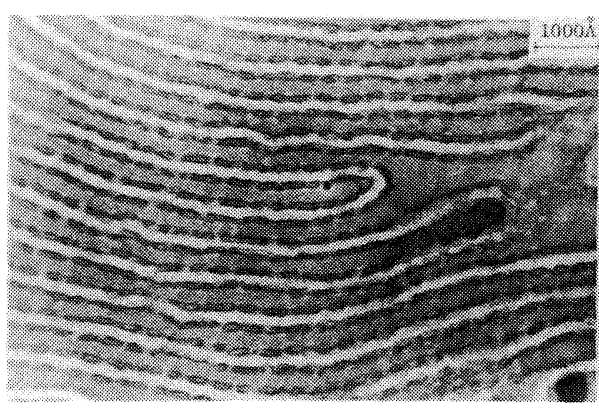

$\mathrm{SBP}-1 /(\mathrm{THF} / \mathrm{MeOH})$

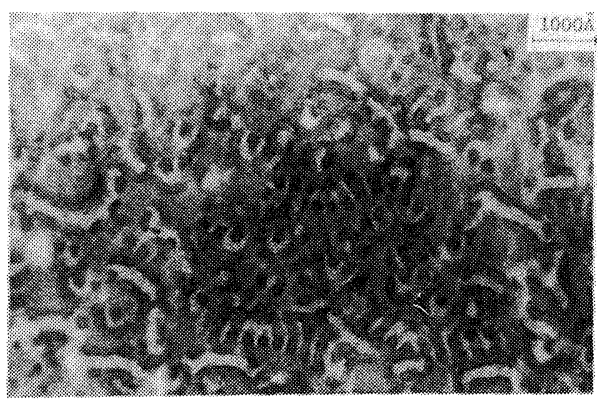

SBP-1/(THF/EtOH)

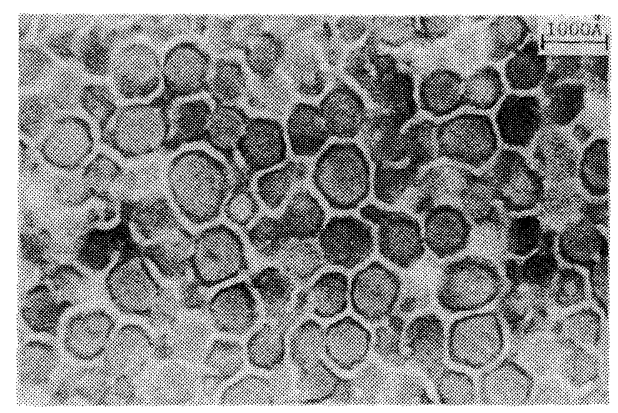

$\mathrm{SBP}-1 /(\mathrm{BZ} / \mathrm{EtOH})$
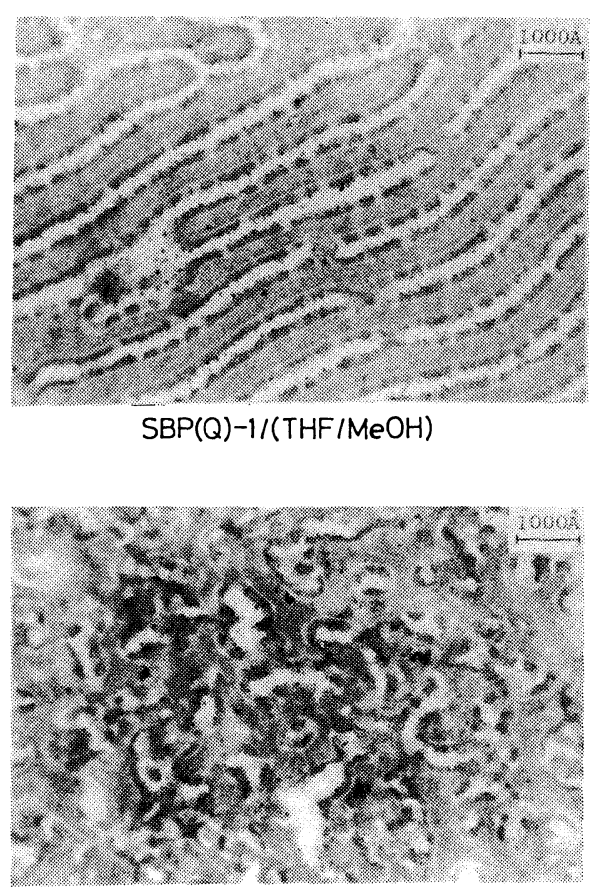

$\operatorname{SBP}(Q)-1 /(T H F / E t O H)$

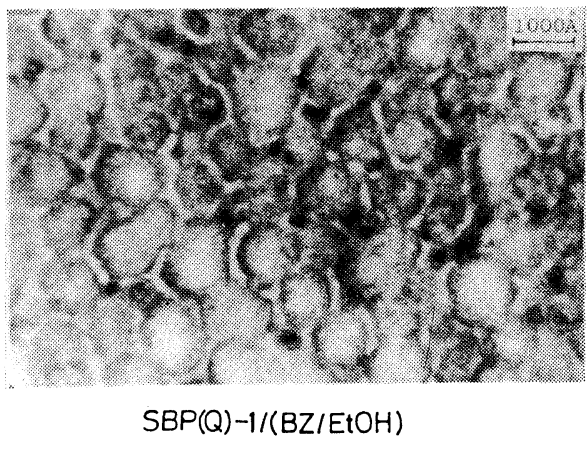

Figure 1. Electron micrographs of SBP-1 cast from THF/MeOH, THF/EtOH, and BZ/EtOH (left) and their quarternizates [SBP(Q)-1] (right) by $\mathrm{CH}_{3} \mathrm{Br}$ vapor at $90^{\circ} \mathrm{C}$ for $14 \mathrm{~h}$.

wormlike, and "ball-in-a-box" structures were observed in specimens cast from $\mathrm{THF} / \mathrm{MeOH}$, $\mathrm{THF} / \mathrm{EtOH}$, and $\mathrm{BZ} / \mathrm{EtOH}$ mixtures, respectively. ${ }^{3}$

$\mathrm{CHCl}_{3}$ cast specimens of SBP-10 and -11 exhibited a "ball-in-a-box" structure, the ball varying in size roughly in proportion to the $2 / 3$ power of the number-average molecular weight $M_{n}{ }^{\mathrm{P}}$ of P4VP blocks. ${ }^{4}$ SBP-10 and -11 specimens cast from THF/MeOH $(4 / 1, v / v)$ exhibited three-layer lamellar type structures. The lamellar structures of $\mathrm{THF} / \mathrm{MeOH}$ cast specimens were usually incomplete and in them, PB blocks formed dotted-line-like layers between the PS and P4VP lamellae. ${ }^{4}$ The details are described in our previous articles. $^{1-4}$

SBP specimens having different composition and morphology were subjected to vapor phase quarternization with $\mathrm{CH}_{3} \mathrm{Br}$. The re- 


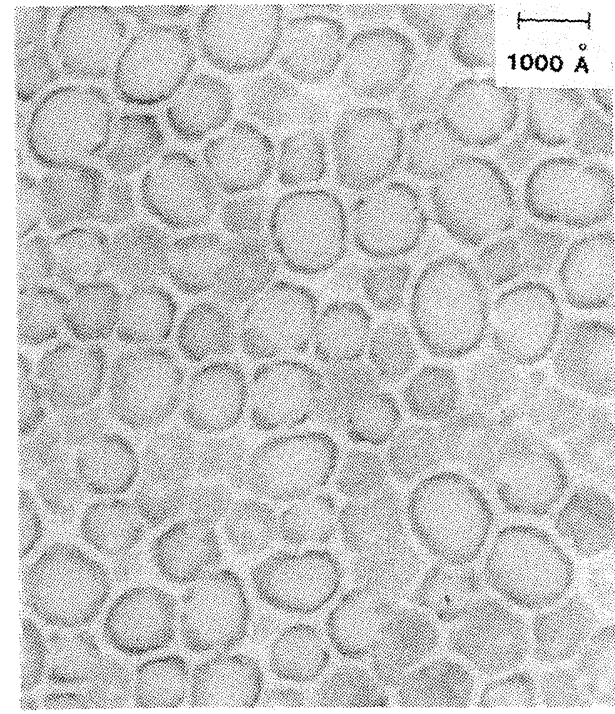

$\mathrm{SBP}-10 / \mathrm{CHCl}_{3}$

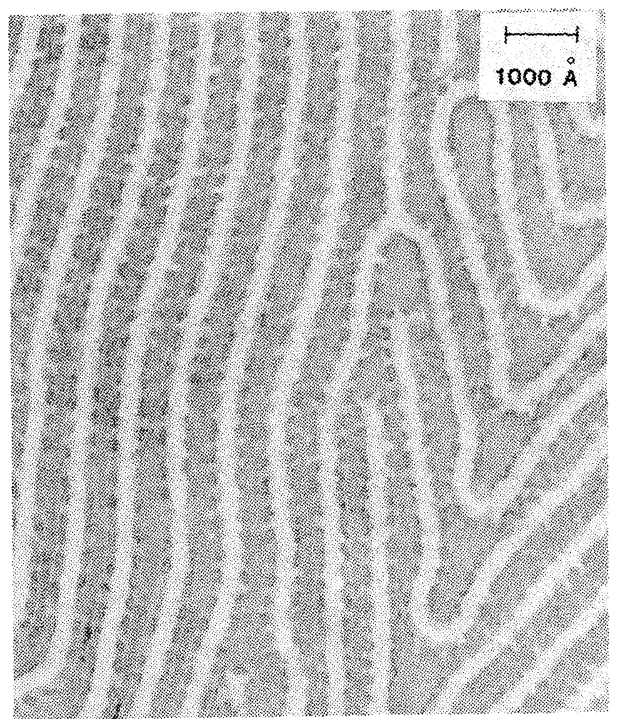

$\mathrm{SBP}-11 /(\mathrm{THF} / \mathrm{MeOH})$

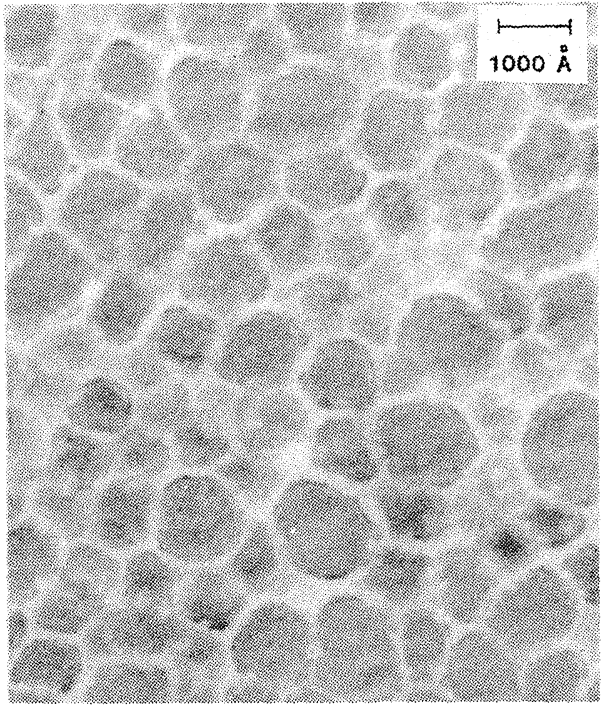

$\operatorname{SBP}(Q)-10 / \mathrm{CHCl}_{3}$

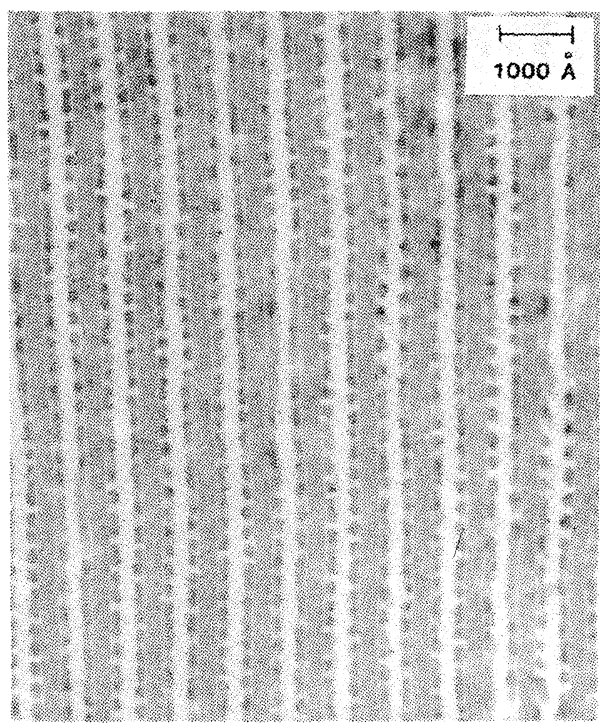

SBP(Q ) - 11/(THF/MeOH)

Figure 2. Electron micrographs of SBP-10 cast from $\mathrm{CHCl}_{3}$ and SBP-11 cast from THF/MeOH (left) and their quarternizates [SBP(Q)-10 and -11 ] (right) by $\mathrm{CH}_{3} \mathrm{Br}$ at $70^{\circ} \mathrm{C}$ for $24 \mathrm{~h}$.

action yield was about $91 \%$ for those quarternized at $90^{\circ} \mathrm{C}$ for a $14 \mathrm{~h}$ reaction, while that for those quarternized at $70^{\circ} \mathrm{C}$ for $24 \mathrm{~h}$ was nearly $100 \%$, regardless of the composition or morphology of the SBP specimens before the reaction. No bromine was detected in the SBS control.

Figure 1 shows electron micrographs for three SBP-1 specimens, coded as SBP-1 and $\mathrm{SBP}(\mathrm{Q})-1$, respectively, before and after the 


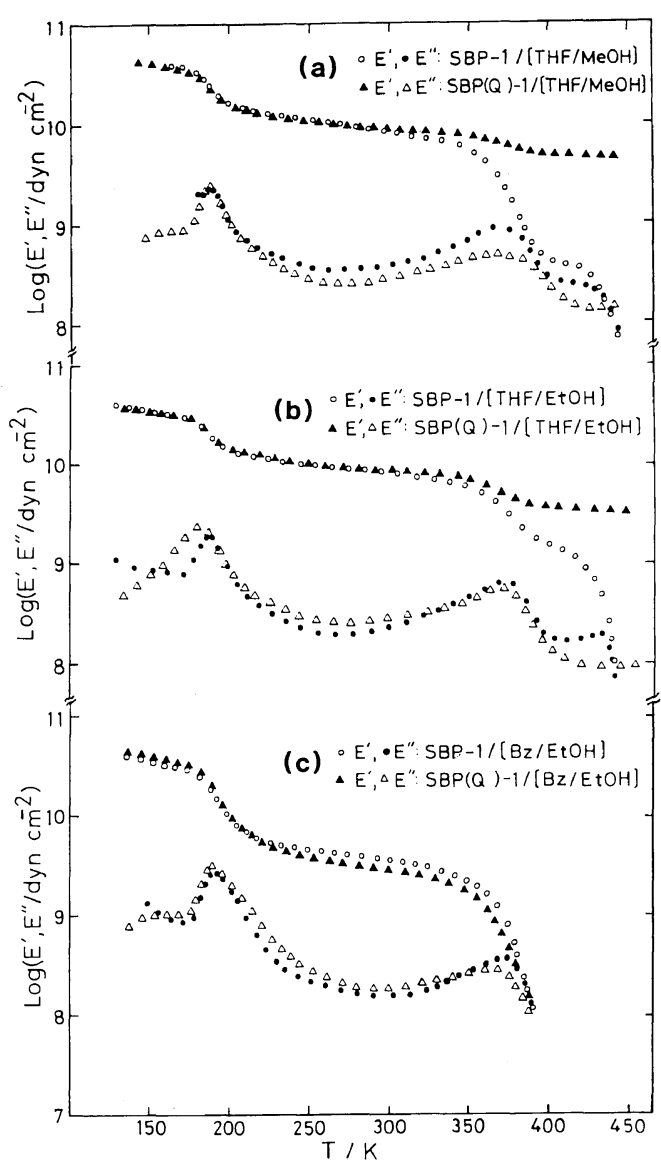

Figure 3. Temperature dependence of storage Young's moduli $E^{\prime}$ and loss moduli $E^{\prime \prime}$ at $110 \mathrm{~Hz}$ of SBP-1 cast from (a) $\mathrm{THF} / \mathrm{MeOH}$, (b) $\mathrm{THF} / \mathrm{EtOH}$, and (c) $\mathrm{BZ} /$ $\mathrm{EtOH}$ and their quarternized $\mathrm{SBP}(\mathrm{Q})-1$ films.

quarternization at $90^{\circ} \mathrm{C}$ for $14 \mathrm{~h}$. Figure 2 shows similar micrographs for SBP-10 cast from $\mathrm{CHCl}_{3}$ and $\mathrm{SBP}-11$ cast from $\mathrm{THF} /$ $\mathrm{MeOH}(4 / 1)$, and then quarternized at $70^{\circ} \mathrm{C}$ for $24 \mathrm{~h}$.

From these micrographs, we see that, in all the samples examined, the original domain shape remain unchanged, but the domain spacings or size of the P4VP balls slightly increased by quarternization. It appears that $\mathrm{CH}_{3} \mathrm{Br}$ molecules selectively reacted with P4VP segments and increased the volume of the P4VP domains. Although osmium tetraoxide does not react with quarternized pyri- dine rings, the quarternized P4VP domains appeared grey. This is presumably due to scattering of electron beams by bromium counter ions.

Figure 3 shows the temperature dependence of dynamic Young's moduli $E^{\prime}$ and loss moduli $E^{\prime \prime}$ for unquarternized SBP-1 and quarternized $\operatorname{SBP}(\mathrm{Q})-1$ specimens. Figure 4 compares the temperature dependence of $E^{\prime}$ and $E^{\prime \prime}$ for $\mathrm{CHCl}_{3}$-cast SBP-10 and THF/ $\mathrm{MeOH}$ (4/1)-cast SBP-11 specimens and their quarternized salts.

The SBP $(\mathrm{Q})$ specimens having "three-layerlamellar" type morphology did not flow even above the glass transition temperature $T_{\mathrm{g}}$ of P4VP (about $430 \mathrm{~K}$ ). ${ }^{2}$ However, the transitions due to PS (about $370 \mathrm{~K}$ ) and PB (about $190 \mathrm{~K}$ ) phases did not change, indicating that $T_{\mathrm{g}}$ of P4VP domains rose to a temperature considerably higher than $T_{\mathrm{g}}$ of the corresponding unquarternized specimens and also that of the P4VP homopolymers. The quarternized P4VP domains appeared to gain the thermomechanical resistance characteristic of ionicallycrosslinked polymers known as ionomers. ${ }^{7}$ Recently, Isono et al. ${ }^{8}$ also found similar hardening by quarternization of multiblock copolymers containing PS, polyisoprene (I), and poly[(4-vinylbenzyl) dimethylamine] (A) of SAI or ISIAI type, in which A segments were quarternized.

Quarternization had no effect on the moduli-temperature curves of $\mathrm{CHCl}_{3}$-cast SBP specimens having "ball-in-a-box" morphology, as can be seen from the two examples in Figures $3 \mathrm{c}$ and $4 \mathrm{a}$. Only two glass transitions assignable to the PS and PB phases were observed for these specimens. It should be noted that even unquarternized specimens having a similar "ball-in-a-box" morphology showed no viscoelastic transition assignable to the P4VP phase. $^{2-4}$

These results were interpreted ${ }^{9}$ as indicating that the isolated P4VP domains surrounded by the soft PB phase contribute little to the bulk tensile moduli at small strain, in contrast to the 


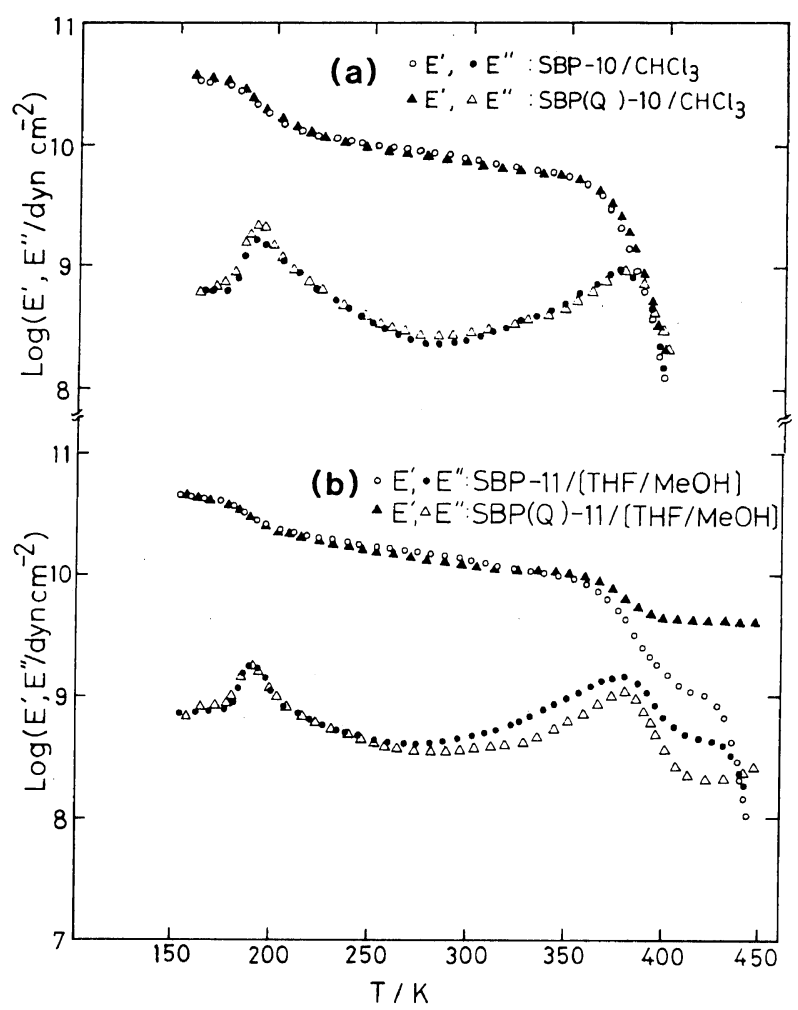

Figure 4. Temperature dependence of storage $E^{\prime}$ and loss $E^{\prime \prime}$ moduli at $110 \mathrm{~Hz}$ of unquarternized (a) $\mathrm{SBP}-10 / \mathrm{CHCl}_{3}$ and (b) SBP-11/[THF/MeOH] and their quarternized specimens, SBP(Q)-10/CHCl ${ }_{3}$ and $\operatorname{SBP}(\mathrm{Q})-11 /[\mathrm{THF} / \mathrm{MeOH}]$.

continuous P4VP lamellae. In a specimen having the "ball-in-a-box" type structure, the mechanical exitation of the matrix phase may not be transmitted to the isolated P4VP domains (having the highest $T_{\mathrm{g}}$ ), but be absorbed and dissipated in the interconnecting PB phase (having the lowest $T_{\mathrm{g}}$ ). ${ }^{9}$ Therefore, the hardening of the P4VP domains by quarternization does not affect the bulk viscoelastic properties of such specimens.

If this interpretation is correct, it should be possible to find the $T_{\mathrm{g}}$ of the P4VP phase by DSC, since the thermal excitation is transmitted to the P4VP phase no matter how the PB phase intervenes. Figure 5 shows typical DSC traces for SBS, SP-2, SBP-10/CHCl 3 and $\mathrm{SBP}(\mathrm{Q})-10 / \mathrm{CHCl}_{3}$ in a temperature range above $300 \mathrm{~K}$. The samples containing P4VP blocks exhibited unusual behavior (see the

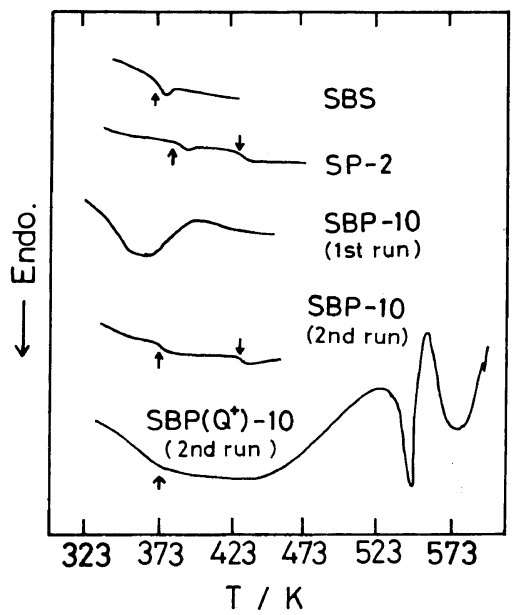

Figure 5. Typical DSC thermograms of SBS, SP-1, SBP- $10 / \mathrm{CHCl}_{3}$ and $\mathrm{SBP}(\mathrm{Q})-10 / \mathrm{CHCl}_{3}$. The arrows $(\uparrow)$ denote the $T_{\mathrm{g}}$ of PS phase and $(\downarrow)$ that of P4VP phase. 
curve for SBP-10 in the figure): an extremely broad endothermic peak in the temperature region from 310 to $370 \mathrm{~K}$ in the first heating process (first run). However, it disappeared in the 2 nd run, and the $T_{\mathrm{g}}$ corresponding to the PS and P4VP phases appeared. This broad peak in the first run may be attributed to the presence of moisture in the specimen. All other unquarternized as well as quarternized SBP specimens (cast from different solvents and hence having different morphology) exhibited essentially similar thermograms.

Two facts are worthy of note. As indicated by one example of a $\mathrm{CHCl}_{3}$-cast $\mathrm{SBP}-10$ specimen in Figure 5, the $T_{\mathrm{g}}$ of the P4VP phase was detected in all the (unquarternized) SBP specimens regardless of the casting solvent used. However, for quarternized SBP(Q) specimens of any structure, no clear $T_{\mathrm{g}}$ corresponding to the P4VP phase could be observed up to about $530 \mathrm{~K}$, at which the specimen began to decompose. This latter finding may be other evidence for the hardening of P4VP domains by quarternization.

Fielding-Russel et $a .^{5}$ Reported that the plateau modulus of a quarternized PS-PBP2VP: $\mathrm{HCl}$ specimen was approximately one order of magnitude higher than that of an ascast unquarternized specimen. However, in all our SBP(Q) specimens cast from any solvent, the plateau moduli between the glass transitions of PS and PB remained unchanged before and after vapor phase quarternization. Summarizing our morphological observations and viscoelastic measurements, we may argue that quarternization does not change the morphology of as-cast films of SBP polymers. This should facilitate the morphological control and increase the scope of applications of SBP polymers.

Acknowledgment. We wish to thank Mr. Kenji Yoshimura, Toray Research Center, for taking the excellent electron micrographs. The work was supported by the Ministry of Education, Science, and Culture (Mombusho) under grants 543026 and 58211010 for which we express our sincere appreciation.

\section{REFERENCES}

1. K. Arai, T. Kotaka, Y. Kitano, and K. Yoshimura, Macromolecules, 13, 455 (1980).

2. K. Arai, T. Kotaka, Y. Kitano, and K. Yoshimura, Macromolecules, 13, 1670 (1980).

3. K. Arai, C. Ueda-Mashima, T. Kotaka, K. Yoshimura, and K. Murayama, Polymer, in press (1983).

4. I. Kudose and T. Kotaka, Macromolecules, submitted (1983).

5. G. S. Fielding-Russel and P. S. Pillai, Polymer, 18, 859 (1977).

6. K. L. Platt and A. Schindler, Angew. Makromol. Chem., 19, 135 (1971).

7. A. Eisenberg, "Ion-Containing Polymers," Academic Press, New York, 1977.

8. Y. Isono, H. Tanisugi, K. Endo, T. Fujimoto, H. Hasegawa, T. Hashimoto, and H. Kawai, Macromolecules, 16, 5 (1983).

9. H. Watanabe and T. Kotaka, Polym. J., 13, 149 (1981). 